\title{
Synthesis of Flavones
}

\author{
Manisha Bansal*, Kulvir Kaur, Jyoti Tomar and Lakhvir Kaur \\ Department of Chemistry, Punjabi University, India
}

Received: November 09, 2017; Published: November 14, 2017

*Corresponding author: Manisha Bansal, Department of Chemsirty, Punjabi University, Patiala-147002, India; Email: Jindal_manisha@yahoo.co.in

\section{Introduction}

Medicinal properties of the plants are attributed due to presence of various flavonoids. Flavone is one class of flavonoids which attracted the attention of researchers worldwide. These 'yellow' colored compounds have 2-phenylchromen-4-one backbone structure. Flavones contribute to various medicinal properties like anti diabetic [1], anti-inflammatory [2], anti-oxidant [3] and anti-cancer [4]. In some basic methods of synthesis of flavones aldehydes react with hydroxyl aceto phenones under claisen- smith condensation. In this review we have tried to summarize the various methods of synthesis of flavones.

\section{Allan-Robinson Strategy of synthesis flavones from chalcone}

Allan $\mathrm{J}$ and Robinson $\mathrm{R}$ [5] carried out the reaction of o-hydroxyaryl ketones with aromatic anhydrides which results in the formation of flavones and isoflavones shown in (Figure 1).

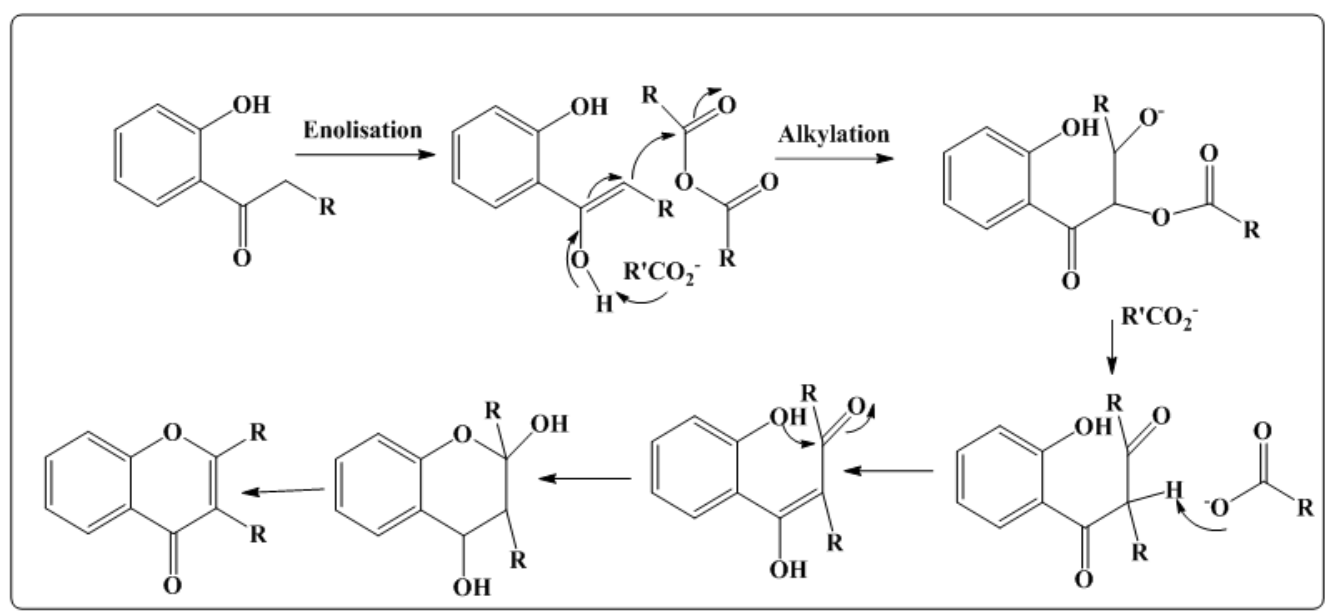

Figure 1: Synthesis of flavoves by Allan Robinson reaction.

O-benzoyloxyacetophenone is heated with glycerol at $2600 \mathrm{C}$ for two hrs which leads to the formation of flvone.

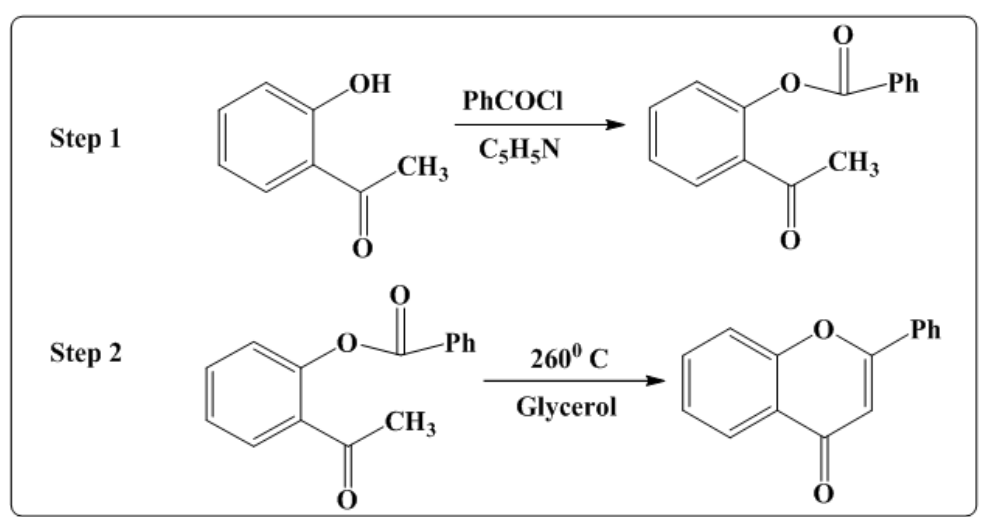

Figure 2: Synthesis of flavones using O-benzoyloxyacetophenone. 


\section{a) Synthesisofflavonesusing0-benzoyloxyacetophenone}

i. Method 1: TSWheeler [6] carried out synthesis of flavones via two step synthesis method. In first step 0-benzoyloxy aceto phenone was synthesized from reaction of 0-hydroxy aceto phenone with benzoyl chloride in the presence of pyridine. In the second step 0-benzoyloxy aceto phenone is heated with glycerol at $2600 \mathrm{C}$ for two hrs which leads to the formation of flvone. The reaction is shown as (Figure 2).

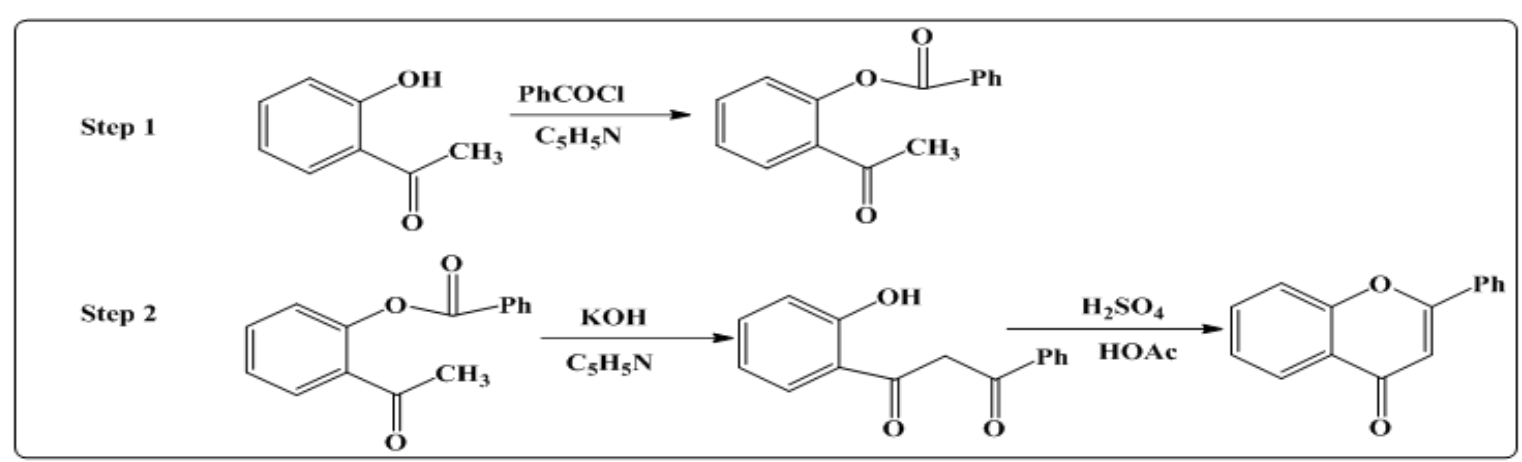

Figure 3: Synthesis of flavones using diketone.

ii. Method 2: In the second method7 first step is same as shown in method 1 . Then in the second step O-benzoyloxyacetophenone was converted into di ketone using
$\mathrm{KOH}$ and pyridine. Then diketone is refluxed with glacial acetic acid and sulphuric acid for $1 \mathrm{hr}$ to obtain the final product as shown in (Figure 3).

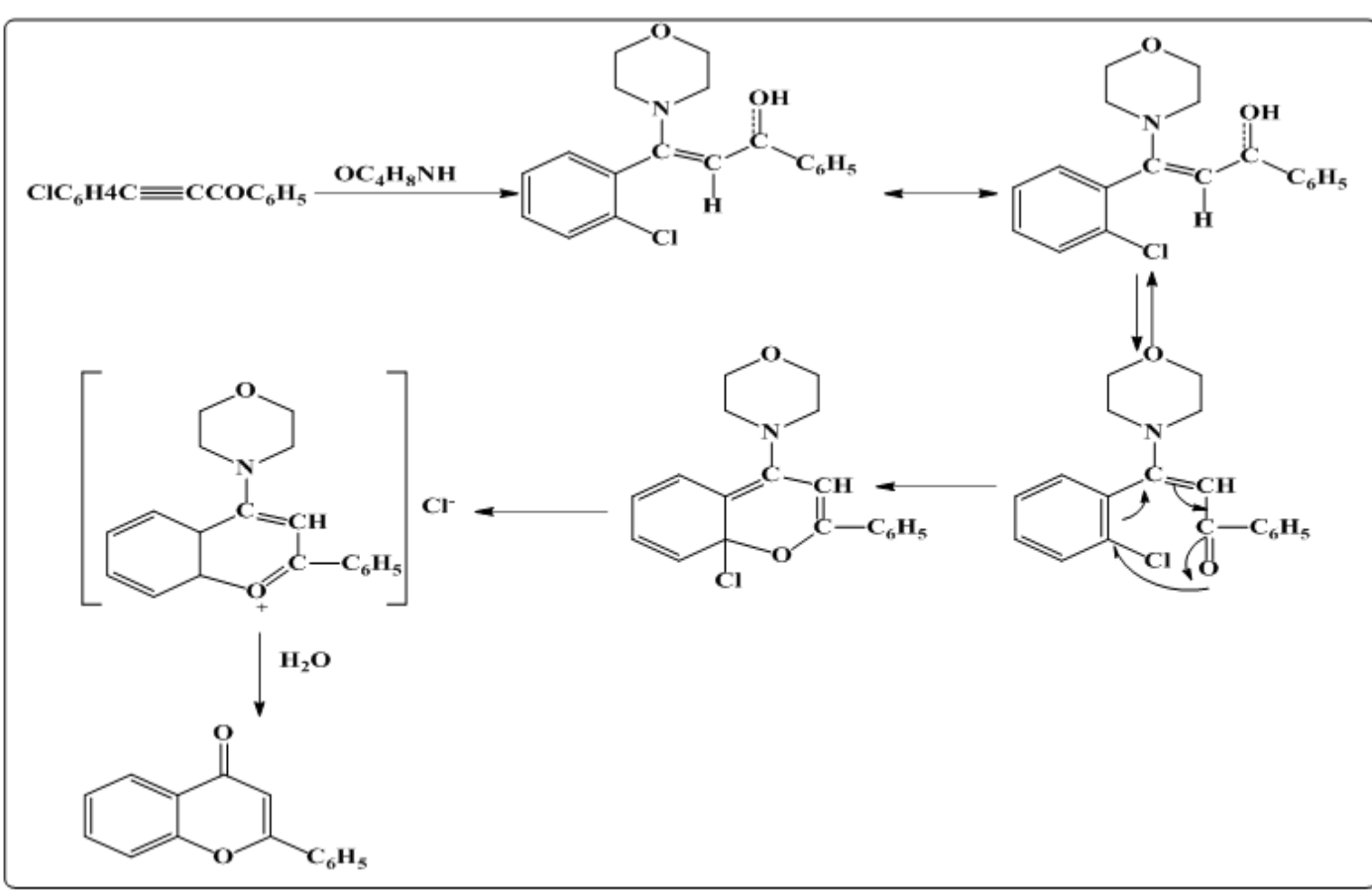

Figure 4: Synthesis of flavones involving cyclization via displacement of aromatic chlorine.<smiles>[Y]C=CC(=O)c1ccccc1O</smiles>

Figure 5: Synthesis of flavones using ium chloropalladite or palladium (II) acetate catalysed reaction.

b) Synthesis of flavones involving cyclization via displacement of aromatic chlorine

In this method [8] 0-chloro phenyl benzoyl acetylene in the presence of morpholine was refluxed for $10 \mathrm{hrs}$ which ends up with the flavone as final product via removal of morpholine hydrochloride. The reaction mechanism is shown as (Figures $4 \& 5)$. 
i. Lithium chloropalladite or palladium (II) acetate catalysed reaction: Initially benzene was stirred with sodium methoxide and then refluxed with Lithium chloropalladite or palladium (II) acetate and at the end reaction results in the formation of flavones [9]. ii. Using LiHDMs and acid catalysed cyclization reaction of $\mathrm{O}$-hydroxyacetophenone: Reaction of O-hydroxyacetophenone with benzoyl chloride under acidic condition using LiHDMs leads to the formation of flavones in addition to the side product [10]. Reaction is shown in (Figure 6).

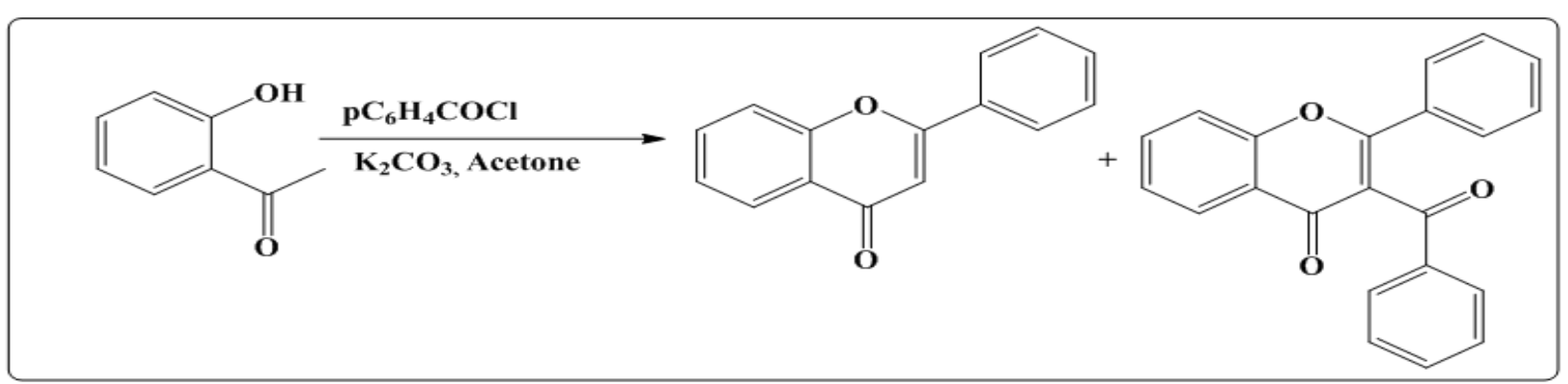

Figure 6: Synthesis of flavones using LiHDMs acid catalysed cyclization reaction of O -hydroxyacetophenone.

\section{iii. Wells-Dawson method of synthesis of flavones using}

Heteropoly acid (HPA): In this method [11] synthesis was carried out using substituted 1,3 diketones dissolved in toluene or solvent free environment. Recation mixture was refluxed for 5 hrs. at room temperature without catalyst $\left(\mathrm{WD}_{40} / \mathrm{SiO}_{2}\right)$ no product was identified on TLC plate whereas use of just $1 \%$ mmol of HPA push the reaction in forward direction as shown in (Figure 7).

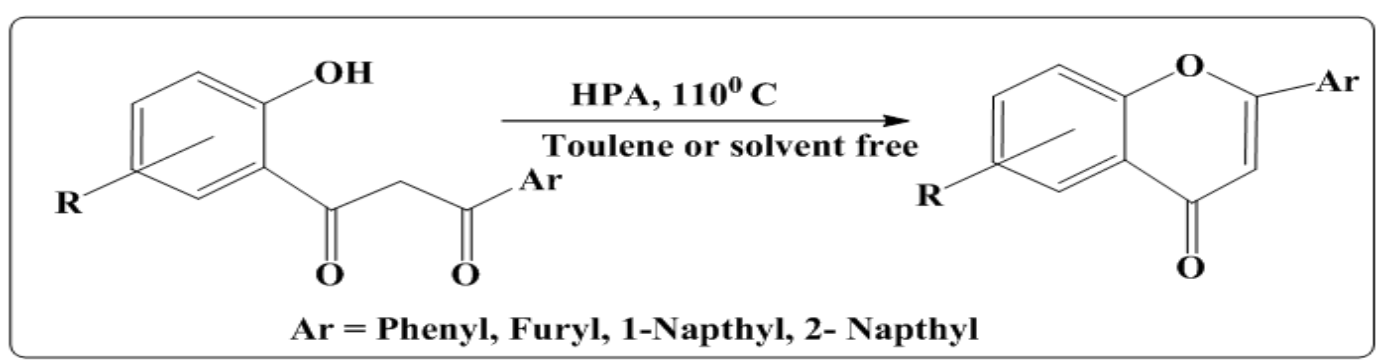

Figure 7: Wells-Dawson method of synthesis of flavones.

iv. From idophenol with alkynes in the presence of pladinum catalyst: Reaction of substituted idophenols with alkynes in the presence of carbon monoxide and pladinum catalyst yielded the flavones [12] as shown in (Figure 8).

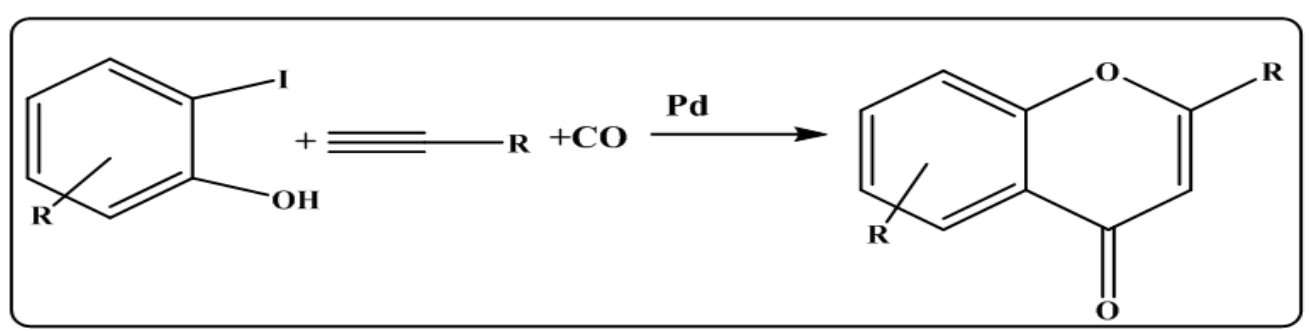

Figure 8: Synthesis of flavones from idophenols and alkynes.

\section{c) Synthesis of flavones from idophenols and alkynes}

i. Iodine-alminium trioxide (I2/Al203) microwave assisted synthesis of flavones: In this method substituted O-hydroxyacetophenones was irradiated in microwave with carboxaldehyde in the presence of I2-Al2O3/ $\mathrm{NaOH}$ [13]. Reaction mechanism is shown in (Figure 8).

ii. From the replacement of alkene hydrogen of $4 \mathrm{H}$-chromen4-one: Reduction of 4H-chromen-4-one in presence of 2,2,6,6-Tetramethylpiperidine (TMP),Zn/ $\mathrm{MgCl}$ and THF gives the flavones as final product [14].

\section{Conclusion}

In this review we attempted to present various methodologies for synthesis of flavones. This review will help to researchers in this field to find the efficient method.

\section{References}

1. Kunimasa K, Kuranuki S, Matsuura N, Iwasaki N, Ikeda M Ito A, et al. (2009) Bioorg Med Chem Lett 19: 2062-2064.

2. Manthey JA, Grohmann K, Montanari A, Ash K, Manthey CLJ (1999) Nat Prod 62: 441-444.

3. Kaur R, Kaur K, Bansal M (2016) Asian Journal of Chemistry 28(9): 1921-1924. 
4. Liu HL, Jiang WB, Xie MX (2010) Flavonoids: recent advances as anticancer drugs. Recent Pat Anticancer Drug Discov 5(2): 152-164.

5. Allan J, Robinson R (1924) J Chem Soc 125: 2192.

6. Wheeler TS (1952) Organic synth 32: 72.

7. Wheeler TS (1952) Organic synth Coll 3: 389.

8. Philip L, Southwick Jack R, Kirchner (1956) J Am Chem Soc 79: 689-691.

9. Kasahara A, Izumi T, Ooshima A (1974) Solution of the chemical society of Japan, 47(10): 2526-2528.
10. Cushman M, Nagarathnam D (1990) Tetrahedron Letters 31: 6497-6500.

11. Bennardi DO, Romanelli GP, Jios JL, Autino JC, Baronetti GT, et al. (2000) J Arkivoc 2008: 123-130.

12. Daniel D, Laetitia M (1995) Tetrahedron Letters 36: 1845-1848.

13. Sarda SR, Jadhav WN, Pawar RP (2009) International Journal of Chem Tech Research 3: 539-543.

14. Lydia K, Tomke B, Tobias A, Nigst K, Knochel KJ (2012) Am Chem Soc 134(33): 13584-13587.

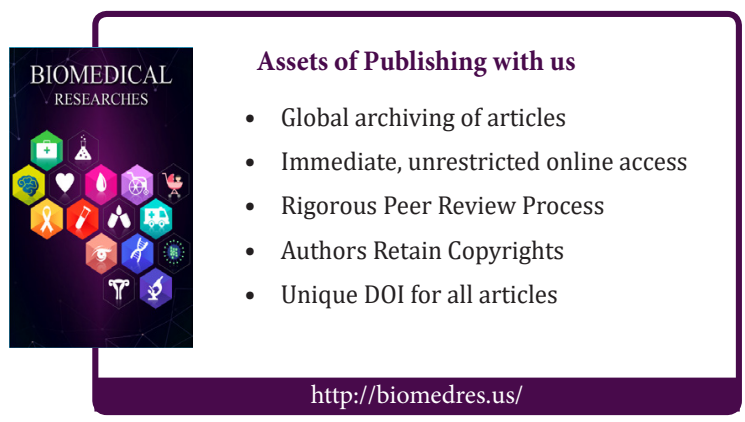

